\title{
Bacteriologically confirmed non-tuberculous mycobacterial lymphadenitis in south east England: a recent increase in the number of cases
}

\author{
J M Grange, M D Yates, A Pozniak
}

\begin{abstract}
The annual numbers of cases of nontuberculous mycobacterial lymphadenitis in south east England has increased over the period 1973 to 1993 , most notably during the last few years. The most frequent cause is the Mycobacterium avium complex, followed by $M$ malmoense. The reason for the increase is unknown but it could be due to an increased awareness in mycobacterial disease, an external factor such as pollution, or both.

(Arch Dis Child 1995; 72: 516-517)
\end{abstract}

Keywords: lymphadenitis, mycobacterium. Mycobacterium avium.

Mycobacterial cervical lymphadenitis, commonly known as scrofula, is usually caused by Mycobacterium tuberculosis or $M$ bovis but in children other species of mycobacteria, especially the $M$ avium complex, are also causative agents. These children are usually under the age of 5 years and commonly present with a single infected lymph node. Unless the patient is immunosuppressed, excision is curative. ${ }^{1}$

We have previously reported an increase in the number of such cases, rising from 43 from $1973-80,{ }^{2}$ to 72 in the period $1981-9 .^{3}$ In recent years we have observed a further increase in the number of such cases, which is reported here in relation to previous years.

\section{Subjects and methods}

Department of Microbiology, National Heart and Lung Institute, London J M Grange

PHLS Regional Tuberculosis Centre, Dulwich Hospital, Dulwich

M D Yates

Directorate of Genitourinary Medicine, King's College Hospital, London A Pozniak

Correspondence to Dr J M Grange, Department of Microbiology, National Heart and Lung Institute, Royal Brompton Hospital, Sydney Street, London SW3 6NP.

Accepted 9 March 1995
Mycobacteria are submitted to the Public Health Laboratory Service South East Regional Tuberculosis Centre, Dulwich, by about 90 client laboratories in south east England. In most cases, these laboratories

Table 1 Number of children at different ages with nontuberculous mycobacterial lymphadenitis due to the $\mathrm{M}$ avium complex and other species

\begin{tabular}{llcl}
\hline $\begin{array}{l}\text { Age } \\
\text { (years) }\end{array}$ & $\begin{array}{l}\text { M avium } \\
\text { complex }\end{array}$ & $\begin{array}{l}\text { Other } \\
\text { species }\end{array}$ & $\begin{array}{l}\text { Total } \\
(\boldsymbol{n}=205)\end{array}$ \\
\hline 1 & 11 & 3 & 14 \\
2 & 38 & 11 & 49 \\
3 & 34 & 10 & 44 \\
4 & 21 & 3 & 24 \\
5 & 20 & 2 & 22 \\
6 & 12 & 2 & 14 \\
7 & 11 & 2 & 13 \\
8 & 6 & 2 & 8 \\
9 & 2 & - & 2 \\
10 & 2 & 2 & 4 \\
11 & 2 & - & 2 \\
12 & 8 & - & 8 \\
13 & - & 1 & 1 \\
\hline
\end{tabular}

supply the name, sex, age, and HIV status of the patient and the site of isolation of the mycobacterium. The ethnic origin (European or non-European) was determined from the names. ${ }^{4}$ In this study, children were defined as those aged up to 16 years.

Mycobacteria were identified by standard reference laboratory methods: that is, by observation of rate of growth, pigment production in light and dark, growth at a range of temperatures, and enzymic activities. ${ }^{5}$

\section{Results}

A total of 205 mycobacteria were received from children with non-tuberculous lymphadenitis: 176 children were of European, and 29 of nonEuropean, ethnic origin. Eighty two were male, 122 were female, and in one case the sex was not stated. A total of 185 isolates $(93 \%)$ were from the cervical region; other sites were preauricular, six isolates; axilla, three; inguinal, four; and unstated, seven. The age distribution is shown in table 1 . The disease was relatively uncommon in those aged 1 year or under but was most prevalent in those aged 2 , after which the number of cases decreased with age, with no cases recorded in those aged 13 to 16 .

The annual number of cases according to species is shown in table $2: 82 \%$ were caused by the $M$ avium complex which, though there were few cases in 1988 and 1989, showed a distinct increase in number from 1990 onwards. Between 1973 and 1989 the mean number of cases due to $M$ avium over this period was 6.8 (95\% confidence interval 4.77 to $8 \cdot 76$ ). The corresponding mean and $95 \%$ confidence interval for numbers in the years $1990-3$ were $22.5(10.1$ to 34.9$)$. Thus the increase in numbers in the final four year period is statistically significant. With the exception $M$ malmoense the numbers of cases caused by other species did not show an increase over time.

Only one patient was reported to be immunosuppressed: a 4 year old HIV positive European boy with M avium infection in 1990.

\section{Discussion}

There is clearly a considerable increase in the number of cultures of $M$ avium from children with lymphadenitis submitted to the Dulwich laboratory since 1990 . There have been no significant changes in the client laboratories referring cultures to Dulwich. It is possible that at least some of the increase in numbers of cultures is an indirect result of the general 
Table 2 Isolation of environmental mycobacteria from cases of lymphadenitis in children, 1973-93

\begin{tabular}{|c|c|c|c|c|c|c|c|c|c|c|c|c|c|c|c|c|c|c|c|c|c|}
\hline \multirow[b]{2}{*}{ Species } & \multicolumn{21}{|c|}{ Year } \\
\hline & 73 & 74 & 75 & 76 & 77 & 78 & 79 & 80 & 81 & 82 & 83 & 84 & 85 & 86 & 87 & 88 & 89 & 90 & 91 & 92 & 93 \\
\hline$M$ avium complex ${ }^{\star}$ & 2 & 8 & 4 & 5 & 2 & 2 & 8 & 6 & 2 & 6 & 13 & 4 & 8 & 9 & 6 & 1 & 2 & 17 & 12 & 22 & 28 \\
\hline$M$ scrofulaceum & - & - & 1 & - & 1 & - & - & 1 & - & - & 1 & - & - & - & 1 & 1 & 1 & - & - & - & - \\
\hline$M$ kansasii & - & - & - & 1 & - & - & - & - & 1 & 1 & - & - & - & - & - & 2 & - & - & - & - & - \\
\hline$M$ malmoense & - & - & - & - & - & - & - & 1 & - & 1 & 1 & - & 2 & 2 & - & 1 & _- & 1 & 1 & 3 & 4 \\
\hline$M$ chelonae & - & - & - & - & - & - & - & - & - & 1 & - & - & - & 1 & - & - & - & 1 & - & - & - \\
\hline$M$ fortuitum & - & - & - & - & - & - & - & - & - & - & - & - & 1 & - & 1 & 1 & - & - & 1 & - & - \\
\hline Other & - & - & - & 1 & - & - & - & - & - & - & 1 & - & - & - & - & - & - & - & - & - & - \\
\hline Total & 2 & 8 & 5 & 7 & 3 & 2 & 8 & 8 & 3 & 9 & 16 & 4 & 11 & 12 & 8 & 6 & 3 & 19 & 14 & 25 & 32 \\
\hline
\end{tabular}

${ }^{\star} M$ avium complex comprising $M$ avium and $M$ intracellulare.

increased awareness in tuberculosis, resulting in more excised lymph nodes being cultured for mycobacteria rather than being placed in formalin for histological examination. The slight increase in the numbers of $M$ malmoense may reflect the general but unexplained increase in the frequency of isolation of this species, mainly from the respiratory tract, throughout Europe over the last two decades. ${ }^{6}$

As $M$ avium and the other species are essentially environmental saprophytes transmitted to human beings by water and possibly, in young children, by ingestion of soil, the number of cases of lymphadenitis may reflect changes in the number of such strains in the environment. Variation over time in the numbers of some environmental mycobacteria in piped water has been demonstrated. As a result of the HIV/AIDS epidemic, there are increasing numbers of adult patients with $M$ avium infection in south east England, ${ }^{7}$ but it is unlikely that these patients are a source of infection for children. Another, but hypothetical, explanation is a weakening of local immunity in the upper respiratory tract by pollution, rendering children more susceptible to disease. At present, the increase in the number of cases remains unexplained but, whatever the cause, this disease requires careful monitoring in the future.

1 Banks J. Environmental mycobacteria. In: Davies PDO, ed. Clinical tuberculosis. London: Chapman and Hall, 1994: 265-75.

2 Grange JM, Collins $\mathrm{CH}$, Yates $\mathrm{MD}$. Bacteriological survey of tuberculous lymphadenitis in south-east England: 1973-80. F Epidemiol Community Health 1982; 36: 157-61.

3 Yates MD, Grange JM. Bacteriological survey of tuberculous lymphadenitis in south-east England, 1981-1989. Epidemiol Community Health 1992; 46: 332-5.

4 Sillito K. Ethnic origin: the search for a question. Population Trends 1978; 13: 25-30.

5 Collins $\mathrm{CH}$, Grange JM, Yates MD. Organization and practice in tuberculosis bacteriology. London: Butterworths 1985. 6 Jenkins PA. Mycobacterium malmoense. Tubercle 1985; 66: 193-5.

7 Yates MD, Pozniak A, Grange JM. Isolation of mycobacteria from patients seropositive for the human immunodefifrom patients seropositive for the human immunodefi-
ciency virus (HIV) in south east England: 1984-1992. ciency virus (HIV) in sou. 